\title{
artigo
}

Araújo Silva, J.C.; Oliveira, E.M.B.; Bezerra, H.R.; Assunção, F.B.R.; Santos Silva, L.A.; Pinheiro, E.S.;

Síndrome de down e aspectos odontológicos

\section{Síndrome de down e aspectos odontológicos}

\section{Down syndrome and dental aspects}

Síndrome down y aspectos dentales

\section{RESUMO}

Objetivo: Revisar artigos disponíveis em periódicos científicos que retratassem os aspectos odontológicos de pacientes com Síndrome de Down. Métodos: Trata-se de um estudo de revisão bibliográfica realizado em 2020, o limite temporal estabelecido para a pesquisa foi entre 2008 a 2018, elegíveis as bases da Biblioteca Digital Brasileira de Teses e Dissertações (BDTD), Coordenação de Aperfeiçoamento de Pessoal de Nível Superior (CAPES) e Google Acadêmico. Conclusão: A partir das informações obtidas podemos concluir que $A$ higiene bucal supervisionada é fundamental nesses indivíduos, devido às limitações motoras e à alta prevalência de doenças periodontais. 0 cirurgião-dentista deve estar preparado para o atendimento de pacientes com necessidades especiais por meio da capacitação técnica e cultivo de valores humanos, minimizando os diversos problemas que esses pacientes já estão condicionados a enfrentar devido ao seu estado de deficiência.

DESCRITORES: Síndrome de Down; Odontologia; Manifestações bucais.

\section{ABSTRACT}

Objective: To review articles available in scientific journals that portrayed the dental aspects of patients with Down Syndrome. Methods: This is a bibliographic review study carried out in 2020, the time limit established for the research was between 2008 to 2018, eligible for the bases of the Brazilian Digital Library of Theses and Dissertations (BDTD), Coordination for the Improvement of Level Personnel Superior (CAPES) and Google Scholar. Conclusion: From the information obtained, we can conclude that supervised oral hygiene is essential in these individuals, due to motor limitations and the high prevalence of periodontal diseases. The dental surgeon must be prepared to assist patients with special needs through technical training and cultivation of human values, minimizing the various problems that these patients are already conditioned to face due to their disability.

DESCRIPTORS: Down syndrome; Dentistry; Oral manifestations.

\section{RESUMEN}

Objetivo: Revisar artículos disponibles en revistas científicas que retratan los aspectos dentales de pacientes con Síndrome de Down. Métodos: Se trata de un estudio de revisión bibliográfica realizado en 2020, el tiempo límite establecido para la investigación fue entre 2008 a 2018, elegible para las bases de la Biblioteca Digital Brasileña de Tesis y Disertaciones (BDTD), Coordinación para el Perfeccionamiento del Personal de Nivel. Superior (CAPES) y Google Scholar. Conclusión: De la información obtenida se puede concluir que la higiene bucal supervisada es fundamental en estos individuos, debido a las limitaciones motoras y la alta prevalencia de enfermedades periodontales. El cirujano dentista debe estar preparado para atender a los pacientes con necesidades especiales mediante la formación técnica y el cultivo de los valores humanos, minimizando los diversos problemas a los que estos pacientes ya están condicionados a afrontar por su discapacidad.

DESCRIPTORES: Síndrome de Down; Odontología; Manifestaciones orales.

RECEBIDO EM: 30/07/2020 APROVADO EM: 01/02/2021

\section{Josanne Christine Araújo Silva}

Bacharel em Nutrição pelo Centro Universitário de Ciências e Tecnologia do Maranhão - UniFacema; Pós-Graduada em Nutrição Clínica, Funcional e Fitoterapia pelo Centro Universitário de Ciências e Tecnologia do Maranhão - UniFacema; Pós-graduada em Gestão e Docência do Ensino Superior pela Faculdade Seven - FAEME.

ORCID: 0000-0003-3181-8406

\section{Erick Michell Bezerra Oliveira}

Bacharel em Fisioterapia na UNIFACEMA-2019. Acadêmico do curso de Odontologia na UNIFACEMA. Pós-graduando em Docência do Ensino Superior com ênfase em sistema de saúde-FAVENI. Pós-Graduando em Gestão Hospitalar e Auditoria em Serviços de Saúde na Estratego Sistema Educacional.

ORCID: 0000-0001-6056-2863 


\section{Hernandys Ribeiro Bezerra}

Acadêmico do curso de Odontologia no Centro Universitário de Ciências e Tecnologia do Maranhão-UNIFACEMA. ORCID: 0000-0001-7261-3920

\section{Flávio Bruno Rodrigues de Assunção}

Acadêmico do curso de Odontologia no Centro Universitário de Ciências e Tecnologia do Maranhão-UNIFACEMA. ORCID: 0000-0001-5982-7542

\section{Letícia Aparecida Santos Silva}

Acadêmico do curso de Odontologia no Centro Universitário de Ciências e Tecnologia do Maranhão-UNIFACEMA. ORCID: 0000-0002-8000-7071

\section{Emerson de Sousa Pinheiro}

Acadêmico do curso de Odontologia no Instituto Florence de Ensino Superior- IFES.

ORCID: 0000-0003-3844-470X

\section{INTRODUÇÃO}

A Síndrome de Down foi descrita, pela primeira vez, pelo médico inglês John Longden Hayden Down, em 1866, sendo na ocasião também denominada de idiotia mongoliana. Porém, apenas em 1959, demonstrou-se que a Síndrome de Down resultava da presença de um cromossomo a mais no par 21 , sendo também denominada de trissomia do cromossomo $21 .^{1,2}$

A síndrome de Down representa a anomalia cromossômica mais comum da espécie humana. Dados comprovam que a Síndrome de Down ocorre uma vez em aproximadamente 800 a 1.200 nascimentos e que, entre zero e quatro anos de idade, a taxa de mortalidade é 52 vezes maior que para a população geral e 37 vezes maior nos primeiros vinte anos de vida. Essa elevada taxa de mortalidade se deve à maior incidência de alterações cardíacas, infecções do aparelho respiratório entre outras complicações advindas de seu próprio metabolismo., ${ }^{1,3}$

A expectativa de vida desses pacientes especiais varia de 35 a 40 anos, mas estima-se que $80 \%$ dos adultos portadores sobrevivam até os 55 anos de idade ou mais. $\mathrm{O}$ diagnóstico da Síndrome de Down baseia-se numa série de sinais e sintomas, sendo sua confirmação estabelecida pelo estudo cromossômico. Nem toda a população afetada apresenta as mesmas características, sendo necessária, no diagnóstico definitivo, uma investigação citogenética para identificação do cariótipo. ${ }^{2,4}$

\section{A expectativa de}

vida desses pacientes

especiais varia de

35 a 40 anos, mas

estima-se que $80 \%$ dos

adultos portadores

sobrevivam até os

55 anos de idade ou

mais. $\mathrm{O}$ diagnóstico

da Síndrome de Down

baseia-se numa série

de sinais e sintomas,

sendo sua confirmação

estabelecida pelo

estudo cromossômico.

O tratamento da Síndrome de Down está estritamente voltado para a manu- tenção da qualidade de vida do portador, prevenindo-se as possíveis complicações. Ressalta-se a importância da colaboração familiar, da equipe multidisciplinar que lida com portadores da síndrome, bem como o empenho do cirurgião-dentista em relação aos aspectos odontológicos destes pacientes. ${ }^{1,4}$

A equipe de profissionais envolvida no cuidado à criança com síndrome de Down deve considerar o papel da odontologia na conquista de melhores condições de vida para esta parcela da população. A saúde bucal ainda é vista com baixa prioridade quando comparada aos cuidados médicos dedicados ao indivíduo acometido pela síndrome. Não é aconselhável que os profissionais que cuidam de pacientes com síndrome de Down deixem os problemas ligados à cavidade bucal em segundo plano.,4

Considerando-se as diversas manifestações sistêmicas e bucais presentes na síndrome de Down, se faz importante que a população acometida seja assistida de forma integral pela equipe de saúde, incluindo a atenção aos aspectos odontológicos. Tendo como perspectiva a prática da integralidade do atendimento, o presente estudo teve por objetivo revisar artigos disponíveis em periódicos científicos que retratassem os aspectos odontológicos de pacientes com Síndrome de Down.

\section{MÉTOdOS}

O presente estudo caracteriza-se como uma revisão integrativa da literatura sobre 


\section{artigo}

Araújo Silva, J.C.; Oliveira, E.M.B.; Bezerra, H.R.; Assunção, F.B.R.; Santos Silva, L.A.; Pinheiro, E.S.

Síndrome de down e aspectos odontológicos

o tema "Síndrome de Down e aspectos odontológicos”. A coleta de dados foi realizada entre os intervalos de 2008 á 2018, e utilizou-se para as pesquisas as bases de dados Biblioteca Digital Brasileira de Teses e Dissertações (BDTD), Coordenação de Aperfeiçoamento de Pessoal de Nível
Superior (CAPES) e Google Acadêmico. A estratégia de busca por artigos nas bases de dados citados foi à utilização dos descritores: "Síndrome de Down, Odontologia, Manifestações bucais".

$\mathrm{Na}$ primeira fase os artigos encontrados passaram pela primeira filtragem

Quadro 1: Análise da estratégia de busca por artigos nas bases de dados citados.

\begin{tabular}{|c|c|c|c|}
\hline & $\begin{array}{c}\text { TOTAL } \\
\text { ENCONTRADO }\end{array}$ & $\begin{array}{c}\text { PRIMEIRA } \\
\text { FILTRAGEM }\end{array}$ & SEGUNDA FILTRAGEM \\
\hline BDTD & 143 & 49 & 5 \\
\hline Google acadêmico & 272 & 124 & 6 \\
\hline CAPES & 225 & 27 & 4 \\
\hline
\end{tabular}

referentes á disponíveis em sua totalidade, publicados entre os anos de 2008 á 2018, nos idiomas português e inglês. Na segunda fase, os filtros analisaram de forma independente se os mesmos estavam condizentes com a temática abordada no presente estudo, sendo observados ainda dados como: nome do autor, ano, objetivos, resultados e discussão. Ao final, foram selecionados para a análise cinco artigos na BDTD, seis artigos na Google Acadêmico e quatro artigos na CAPES, totalizando, no final, 15 trabalhos utilizados.

\section{RESULTADOS}

Quadro 2. Análises descritivas das produções científicas acerca da Síndrome de Down e aspectos odontológicos. Caxias- MA, 2018.

\begin{tabular}{|c|c|c|c|c|c|}
\hline TÍTULO DO ARTIGO & $\begin{array}{l}\text { AUTOR/ } \\
\text { AUTORES }\end{array}$ & $\begin{array}{c}\text { ANO DE } \\
\text { PUBLICAÇÃO }\end{array}$ & OBJETIVO & $\begin{array}{l}\text { TIPO DE } \\
\text { ESTUDO }\end{array}$ & RESULTADOS \\
\hline $\begin{array}{c}\text { Crescimento de } \\
\text { crianças e adoles- } \\
\text { centes com Síndro- } \\
\text { me de Down - Uma } \\
\text { breve revisão de } \\
\text { literatura }\end{array}$ & Gorla et al & 2011 & $\begin{array}{l}\text { Realizar uma revisão da } \\
\text { literatura sobre curvas } \\
\text { de crescimento de } \\
\text { sujeitos com Síndrome } \\
\text { de Down (SD) }\end{array}$ & $\begin{array}{l}\text { Revisão de } \\
\text { Literatura }\end{array}$ & $\begin{array}{l}\text { Os resultados demonstram um cresci- } \\
\text { mento aproximado em -1.5 a -4 desvios } \\
\text { padrão em sujeitos com SD, quando } \\
\text { comparado à população típica, iniciada } \\
\text { esta diferença durante a fase pré-natal } \\
\text { e se estendendo até a idade adulta. } \\
\text { Não ocorrendo alterações de grandes } \\
\text { amplitudes entre estudos de diferentes } \\
\text { nacionalidades. }\end{array}$ \\
\hline $\begin{array}{l}\text { Special Care } \\
\text { Dentistry } \\
\text { Association } \\
\text { consensus } \\
\text { statement } \\
\text { on sedation, } \\
\text { anesthesia } \\
\text { and alternative } \\
\text { techniques for } \\
\text { people with special } \\
\text { needs. }\end{array}$ & $\begin{array}{l}\text { Glassman } \\
\text { et al. }\end{array}$ & 2009 & $\begin{array}{l}\text { Enfocar o processo } \\
\text { de tomada de decisão } \\
\text { para a escolha de um } \\
\text { método de tratamento } \\
\text { ou uma combinação de } \\
\text { métodos para facilitar } \\
\text { o tratamento dentário } \\
\text { para esses indivíduos. }\end{array}$ & $\begin{array}{c}\text { Estudo } \\
\text { descritivo } \\
\text { exploratório }\end{array}$ & $\begin{array}{l}\text { Muitos desses indivíduos requerem } \\
\text { suportes adicionais além da anestesia } \\
\text { local para receber serviços de } \\
\text { tratamento odontológico. O propósito } \\
\text { deste consenso declaração é focar no } \\
\text { processo de tomada de decisão para a } \\
\text { escolha de um método de tratamento } \\
\text { ou uma combinação de métodos para } \\
\text { facilitar o tratamento dentário para } \\
\text { estes indivíduos. }\end{array}$ \\
\hline $\begin{array}{l}\text { Conhecimento da } \\
\text { habilidade motora } \\
\text { e fatores clínicos } \\
\text { de crianças com } \\
\text { síndrome de Down } \\
\text { e a sobrecarga de } \\
\text { seus cuidadores. }\end{array}$ & $\begin{array}{l}\text { Lace; } \\
\text { Martins }\end{array}$ & 2014 & $\begin{array}{l}\text { Avaliar o desempenho } \\
\text { motor e as característi- } \\
\text { cas clínicas de crianças } \\
\text { com síndrome de } \\
\text { Down e conhecimen- } \\
\text { to das mães sobre o } \\
\text { desempenho motor de } \\
\text { seus filhos. }\end{array}$ & $\begin{array}{l}\text { Estudo } \\
\text { exploratório } \\
\text { descritivo }\end{array}$ & $\begin{array}{l}\text { O grupo de mães das crianças com } \\
\text { síndrome de Down compunha uma } \\
\text { amostra com média de idade de } 28 \pm 4,5 \\
\text { anos, em } 55 \% \text { a gravidez não foi plane- } \\
\text { jada e } 95 \% \text { tiveram conhecimento sobre } \\
\text { o diagnóstico após o nascimento, } 80 \% \\
\text { sem intercorrências durante a gravidez e } \\
\text { 45\% nunca ouviram falar sobre síndrome } \\
\text { de Down. As alterações ortopédicas } \\
\text { foram as mais prevalentes e a sobrecar- } \\
\text { ga na qualidade de vida das mães dos } \\
\text { grupos das crianças com síndrome de } \\
\text { Down foi moderada ( } 22,5 \pm 10,6) \text {. }\end{array}$ \\
\hline
\end{tabular}




\begin{tabular}{|c|c|c|c|c|c|}
\hline $\begin{array}{l}\text { Síndrome de Down: } \\
\text { aspectos relacio- } \\
\text { nados ao sistema } \\
\text { estomatognático. }\end{array}$ & $\begin{array}{l}\text { Carvalho, } \\
\text { Campos, } \\
\text { Crusoé- } \\
\text {-Rebello }\end{array}$ & 2010 & $\begin{array}{c}\text { Realizar uma revisão de } \\
\text { literatura sobre as prin- } \\
\text { cipais características do } \\
\text { sistema Estomatogná- } \\
\text { tico apresentadas pelos } \\
\text { pacientes portadores } \\
\text { da Síndrome de Down, } \\
\text { destacando a parti- } \\
\text { cipação do cirurgião- } \\
\text {-dentista numa equipe } \\
\text { multidisciplinar respon- } \\
\text { sável pela promoção da } \\
\text { saúde. }\end{array}$ & $\begin{array}{l}\text { Revisão de } \\
\text { Literatura }\end{array}$ & $\begin{array}{l}\text { Ressalte-se a importância da conscienti- } \\
\text { zação familiar acerca da necessidade de } \\
\text { higienização bucal para esses pacientes, } \\
\text { bem como do conhecimento pelo cirurgião } \\
\text { dentista acerca das principais manifesta- } \\
\text { ções bucais que acometem os pacientes } \\
\text { portadores, para que o tratamento ade- } \\
\text { quado seja oferecido e a qualidade de vida } \\
\text { desses indivíduos preservada. }\end{array}$ \\
\hline $\begin{array}{l}\text { Uso de serviços } \\
\text { odontológicos por } \\
\text { pacientes com sín- } \\
\text { drome de Down }\end{array}$ & $\begin{array}{c}\text { Oliveira et } \\
\text { al., }\end{array}$ & 2008 & $\begin{array}{l}\text { Analisar os fatores } \\
\text { relacionados à atenção } \\
\text { odontológica recebida } \\
\text { por crianças e adoles- } \\
\text { centes com síndrome } \\
\text { de Down. }\end{array}$ & $\begin{array}{l}\text { Estudo de cor- } \\
\text { te transversal }\end{array}$ & $\begin{array}{c}\text { A maioria dos sindrômicos }(79,5 \%) \text { já tinha } \\
\text { ido pelo menos uma vez ao dentista (IC } \\
90 \%: 72,3 ; 87,8) \text {. A experiência odontológi- } \\
\text { ca das crianças foi associada às variáveis: } \\
\text { mães que afirmaram receber orientação de } \\
\text { algum profissional, que assiste seu filho, } \\
\text { para que o levasse ao dentista (OR=6,1 } \\
[2,5 ; 15,1]) \text {, crianças/adolescentes com } \\
\text { história prévia de cirurgia (OR=2,5 }[0,9 ; \\
7,1] \text { ) e idade entre } 12 \text { e } 18 \text { anos (OR=13,1 } \\
[2,0 ; 86,9]) \text {. }\end{array}$ \\
\hline $\begin{array}{l}\text { Importância da } \\
\text { abordagem precoce } \\
\text { no tratamento } \\
\text { odontológico de pa- } \\
\text { cientes com neces- } \\
\text { sidades especiais. }\end{array}$ & $\begin{array}{l}\text { Oliveira; } \\
\text { Giro. }\end{array}$ & 2010 & $\begin{array}{l}\text { Realizar uma revisão } \\
\text { da literatura a respeito } \\
\text { da importância da } \\
\text { abordagem precoce no } \\
\text { tratamento odontoló- } \\
\text { gico de pacientes com } \\
\text { necessidades especiais. }\end{array}$ & $\begin{array}{l}\text { Revisão de } \\
\text { Literatura }\end{array}$ & $\begin{array}{l}\text { O cirurgião-dentista deve estar preparado } \\
\text { para o atendimento de pacientes com } \\
\text { necessidades especiais por meio da capaci- } \\
\text { tação técnica e cultivo de valores humanos, } \\
\text { minimizando os diversos problemas que } \\
\text { esses pacientes já estão condicionados a } \\
\text { enfrentar devido ao seu estado de defici- } \\
\text { ência. }\end{array}$ \\
\hline $\begin{array}{l}\text { Avaliação do trata- } \\
\text { mento odontoló- } \\
\text { gico de pacientes } \\
\text { com necessidades } \\
\text { especiais sob anes- } \\
\text { tesia geral. }\end{array}$ & $\begin{array}{l}\text { Castro et } \\
\text { al., }\end{array}$ & 2010 & $\begin{array}{l}\text { Avaliar o tratamento } \\
\text { odontológico de pa- } \\
\text { cientes com necessi- } \\
\text { dades especiais sob } \\
\text { anestesia geral. }\end{array}$ & $\begin{array}{l}\text { Estudo } \\
\text { exploratório } \\
\text { descritivo }\end{array}$ & $\begin{array}{l}\text { A maioria dos pacientes }(98,32 \%) \text { foi } \\
\text { classificada como ASA II. Nos } 119 \text { prontu- } \\
\text { ários constatou-se que: em } 92 \text { pacientes } \\
(77,31 \%) \text { foram realizadas } 501 \text { restaura- } \\
\text { ções; em } 89 \text { ( } 74,79 \%) 602 \text { extrações; em } \\
69(57,83 \%) \text { raspagem supra / subgengival; } \\
\text { em } 37(31,09 \%) 100 \text { selantes de fossas e } \\
\text { fissuras; em } 2(1,68 \%) 4 \text { pulpotomias; em } 1 \\
(0,84 \%) 1 \text { pulpectomia, e em } 1(0,84 \%) \text { gen- } \\
\text { givectomia. As consultas de revisão para } \\
\text { manutenção preventiva foram realizadas } \\
\text { principalmente em ambulatório }(83,10 \%) \text {. }\end{array}$ \\
\hline $\begin{array}{l}\text { Perspectivas de } \\
\text { abordagem a crian- } \\
\text { ça com Sindrome } \\
\text { de Down: uma re- } \\
\text { visão integrativa da } \\
\text { literatura Universi- } \\
\text { dade de Brasilia. }\end{array}$ & Santos & 2014 & $\begin{array}{l}\text { Apresentar as evidên- } \\
\text { cias científicas dis- } \\
\text { poniveis na literatura } \\
\text { sobre assistência de } \\
\text { enfermagem à criança } \\
\text { com Síndrome de } \\
\text { Down no período de } \\
2009 \text { a } 2013 .\end{array}$ & $\begin{array}{l}\text { Revisão de } \\
\text { Literatura }\end{array}$ & $\begin{array}{l}\text { Os artigos abordavam três temas que eram } \\
\text { de fácil percepção: atenção direta a criança, } \\
\text { atenção à familia e trabalho dos profis- } \\
\text { sionais de saúde. A atenção à família foi o } \\
\text { tema que apresentou o maior número de } \\
\text { publicações, devido a dependência de toda } \\
\text { criança em relação aos pais ser algo espe- } \\
\text { rado e uma maior dependência ainda de } \\
\text { uma criança com SD, sendo assim a maioria } \\
\text { das publicações se voltou a lidar com os } \\
\text { pais e através deles possibilitar o cuidado. }\end{array}$ \\
\hline
\end{tabular}




\section{artigo}

Araújo Silva, J.C.; Oliveira, E.M.B.; Bezerra, H.R.; Assunção, F.B.R.; Santos Silva, L.A.; Pinheiro, E.S.;

Sindrome de down e aspectos odontológicos

\begin{tabular}{|c|c|c|c|c|c|}
\hline $\begin{array}{l}\text { Programa de assis- } \\
\text { tência odontológica } \\
\text { ao paciente espe- } \\
\text { cial: uma experiên- } \\
\text { cia de } 13 \text { anos }\end{array}$ & Marta & 2011 & $\begin{array}{l}\text { Compartilhar a expe- } \\
\text { riência de } 13 \text { anos do } \\
\text { Programa de Assis- } \\
\text { tência Odontológica ao } \\
\text { Paciente Especial da } \\
\text { Universidade Sagrado } \\
\text { Coração, abordando o } \\
\text { protocolo de tratamen- } \\
\text { to utilizado tanto para o } \\
\text { tratamento ambulato- } \\
\text { rial quanto o hospitalar, } \\
\text { sob anestesia geral } \\
\text { com atuação integrada } \\
\text { de uma equipe multi- } \\
\text { profissional envolvendo } \\
\text { os alunos de graduação } \\
\text { em Odontologia. }\end{array}$ & $\begin{array}{l}\text { Estudo quanti- } \\
\text { tativo }\end{array}$ & $\begin{array}{l}\text { Realização de } 23.646 \text { procedimentos cirúr- } \\
\text { gico-restauradores e preventivos; compro- } \\
\text { metimento das familias com o programa de } \\
\text { saúde bucal; envolvimento acentuado dos } \\
\text { alunos de graduação em Odontologia. }\end{array}$ \\
\hline $\begin{array}{l}\text { Oral health of } \\
\text { patients with intel- } \\
\text { lectual disabilities }\end{array}$ & O'Keefe & 2010 & $\begin{array}{c}\text { Revisar a literatura } \\
\text { sobre a saúde bucal de } \\
\text { adultos com deficiência } \\
\text { intelectual. }\end{array}$ & $\begin{array}{l}\text { Revisão de } \\
\text { literatura }\end{array}$ & $\begin{array}{c}\text { Os estudos eram variáveis qualidade com } \\
\text { muitos sendo de um tamanho de amostra } \\
\text { pequeno. Pessoas com identidade eram } \\
\text { encontrado para ter má higiene bucal e } \\
\text { maior prevalência e maior gravidade da } \\
\text { doença periodontal. As taxas de cárie em } \\
\text { pessoas com ID são as igual ou inferior à } \\
\text { população em geral. As taxas de não tra- } \\
\text { tado cáries são consistentemente maiores } \\
\text { em pessoas com DI }\end{array}$ \\
\hline $\begin{array}{l}\text { Dental hygiene } \\
\text { education about } \\
\text { patients with spe- } \\
\text { cial needs: a survey } \\
\text { of U.S. programs. }\end{array}$ & $\begin{array}{l}\text { Dehaitem } \\
\text { et al., }\end{array}$ & 2008 & $\begin{array}{l}\text { Explorar como os pro- } \\
\text { gramas de higiene den- } \\
\text { tal nos Estados Unidos } \\
\text { educam seus alunos } \\
\text { sobre o tratamento de } \\
\text { pacientes com necessi- } \\
\text { dades especiais. }\end{array}$ & $\begin{array}{l}\text { Estudo de cor- } \\
\text { te transversal }\end{array}$ & $\begin{array}{l}\text { Os entrevistados identificaram a "sobre- } \\
\text { carga curricular" como o maior desafio para } \\
\text { atender às necessidades especiais dos } \\
\text { pacientes. No entanto, } 29,4 \text { por cento dos } \\
\text { entrevistados indicaram que apoiam um } \\
\text { aumento nas experiências clínicas para os } \\
\text { alunos para dar-lhes mais oportunidades } \\
\text { de trabalhar com pacientes com necessida- } \\
\text { des especiais. }\end{array}$ \\
\hline $\begin{array}{l}\text { Cost as a barrier } \\
\text { to dental care } \\
\text { among people with } \\
\text { disabilities: a report } \\
\text { from the Florida } \\
\text { behavioral risk } \\
\text { factor surveillance } \\
\text { system. }\end{array}$ & $\begin{array}{l}\text { Rapallo et } \\
\text { al., }\end{array}$ & 2010 & $\begin{array}{l}\text { Relatar o custo do } \\
\text { cuidado como uma } \\
\text { barreira para a saúde } \\
\text { bucal. }\end{array}$ & $\begin{array}{l}\text { Revisão de } \\
\text { literatura }\end{array}$ & $\begin{array}{l}\text { Mais pessoas com deficiência relataram } \\
\text { não consultar um dentista devido ao custo } \\
\text { do que pessoas sem deficiência ( } 30 \% \text { vs. } \\
16 \% \text { ). Depois de ajustar para variáveis de } \\
\text { confusão, Floridians com deficiência foram } \\
60 \% \text { mais propensos a relatar o custo como } \\
\text { uma barreira para o atendimento odontoló- } \\
\text { gico (OR = 1,60, IC } 95 \% 1,32-1,94 \text { ). }\end{array}$ \\
\hline $\begin{array}{l}\text { Factors affecting } \\
\text { the oral condition } \\
\text { of patients with } \\
\text { severe motor and } \\
\text { intellectual disabi- } \\
\text { lities. }\end{array}$ & $\begin{array}{c}\text { Idaiara et } \\
\text { al., }\end{array}$ & 2008 & $\begin{array}{c}\text { Investigar os fatores } \\
\text { específicos relaciona- } \\
\text { dos à ocorrência de cá- } \\
\text { rie dentária e extrações } \\
\text { dentárias em pacientes } \\
\text { com deficiência motora } \\
\text { e intelectual grave } \\
\text { (PSMI) residentes em } \\
\text { uma instituição. }\end{array}$ & $\begin{array}{l}\text { Estudo de cor- } \\
\text { te transversal }\end{array}$ & $\begin{array}{l}\text { Pela análise multivariada, a ruminação e a } \\
\text { alimentação por sonda foram identificadas } \\
\text { como fatores significativos associados à } \\
\text { nova cárie dentária. Por outro lado, a in- } \\
\text { fância ou deficiência na infância e salivação } \\
\text { foram identificados como fatores significa- } \\
\text { tivos relacionados à extração dentária. }\end{array}$ \\
\hline
\end{tabular}




\begin{tabular}{|c|c|c|c|c|c|}
\hline $\begin{array}{l}\text { Oral health of } \\
\text { patients intellec- } \\
\text { tual disabilities: a } \\
\text { systematic review. } \\
\text { Spec Care Dent. }\end{array}$ & $\begin{array}{l}\text { Anders, } \\
\text { Davis }\end{array}$ & 2010 & $\begin{array}{l}\text { Determinar se existem } \\
\text { diferenças na saúde } \\
\text { bucal entre adultos } \\
\text { com deficiência intelec- } \\
\text { tual (ID) e a população } \\
\text { em geral. }\end{array}$ & $\begin{array}{l}\text { Revisão Siste- } \\
\text { mática }\end{array}$ & $\begin{array}{l}\text { As taxas de cárie em pessoas com DI são } \\
\text { iguais ou inferiores às da população em } \\
\text { geral. No entanto, as taxas de cárie não } \\
\text { tratada são consistentemente mais altas } \\
\text { em pessoas com DI. Dois subgrupos de } \\
\text { risco especialmente alto para problemas } \\
\text { de saúde bucal são pessoas com síndrome } \\
\text { de Down e pessoas incapazes de cooperar } \\
\text { com o atendimento odontológico de rotina. }\end{array}$ \\
\hline $\begin{array}{l}\text { Tooth-brushing } \\
\text { intervention } \\
\text { programme among } \\
\text { children with men- } \\
\text { tal handicap }\end{array}$ & $\begin{array}{l}\text { Stefano- } \\
\text { vska et al., }\end{array}$ & 2010 & $\begin{array}{l}\text { Proporcionar inter- } \\
\text { venção de escovação } \\
\text { dentária em crianças } \\
\text { com deficiência mental }\end{array}$ & $\begin{array}{l}\text { Estudo de cor- } \\
\text { te transversal }\end{array}$ & $\begin{array}{l}\text { Para análises comparativas dos níveis de } \\
\text { base de dados de OHI e após seis meses } \\
\text { do programa de intervenção, detectamos } \\
\text { que o nível médio do índice de base de } \\
\text { dados de OHI para crianças com deficiência } \\
\text { mental é de } 2,46, \text { e no final do programa } \\
\text { (após seis meses) era } 0,73 \text {. Os níveis do } \\
\text { índice CPITN no início e após seis meses } \\
\text { de intervenção programada para crianças } \\
\text { com deficiência mental em ambas as faixas } \\
\text { etárias, também confirmaram significância } \\
\text { estatística para este parâmetro examinado, } \\
\text { com redução evidente dos níveis médios } \\
\text { do CPITN de } 2,11 \text { para 0,95. A correlação } \\
\text { entre os níveis de OHI com base em datas } \\
\text { e os niveis no final do nosso programa de } \\
\text { intervenção significa uma alta correlação } \\
\text { positiva entre esses níveis de índice nos } \\
\text { exames inicial e final. }\end{array}$ \\
\hline
\end{tabular}

\section{DISCUSSÃO}

Cada célula de um indivíduo comum possui 46 cromossomos, que estão divididos em 23 pares, no indivíduo com Síndrome de Down, o par de número 21 possui um cromossomo a mais, resultando em 47 cromossomos. Gorla et al., (2011) retrata em seu estudo que existem três tipos de anomalias variantes na SD, a mais comum é a Trissomia do cromossomo 21 por não disjunção meiótica, que ocorre em cerca de $95 \%$ dos portadores, o segundo tipo é a translocação, afetando aproximadamente $3 \%$ dos portadores, e o terceiro tipo é conhecido como mosaico, com uma incidência de $2 \%$.

De acordo com Glassman e colaboradores $(2009)^{5}$, alguns aspectos podem estar associados a ampliação da possibilidade do nascimento de um filho com SD, dentre eles podemos citar a idade materna de 35 ou mais, pois a partir dessa idade, o risco de ter um filho com anormalidade cromossômica dobra a cada dois anos e meio, embora não seja descartado o nascimento de crianças com síndrome de Down entre mães jovens; a idade paterna de 45 anos ou mais; nascimento anterior de uma criança com SD ou outra anormalidade cromossômica; translocação cromossômica balanceada em um dos pais; e pais com desordens cromossômicas. ${ }^{1,2}$

Para Lace e Martins (2014) ${ }^{6}$, O diagnóstico pré-natal é possivelmente realizado por meio de cariotipagem fetal. A síndrome de Down também pode ser diagnosticada após o nascimento da criança em razão do reconhecimento de seus principais fenótipos, como: hipotonia muscular generalizada, occipital achatado, pescoço curto e grosso, prega única na palma das mãos, comprometimento no comprimento e retardo mental. No entanto, como citado no estudo de Carvalho, Campos e Crusoé-Rebello $(2010)^{7}$, nota-se ainda pouco conhecimento da patologia pelos familiares que nem sempre sabem que a criança é portadora desta síndrome.

Uma série de patologias associadas in- terferem no desenvolvimento desses indivíduos. Referente á esta informação, o estudo de Oliveira et al., $(2008)^{8}$ retrata que pacientes com síndrome de down necessitam de exames exclusivos para serem diagnosticados, tais como anomalias de audição (em aproximadamente $80 \%$ dos casos), alterações ortodônticas (80\%), anomalias da visão (50\%), anomalias cardíacas ( 40 a 50\%), alterações endocrinológicas (15 a 25\%), anomalias do aparelho locomotor (15\%), alterações neurológicas (8\%), alterações hematológicas (3\%), anomalias do aparelho digestivo (12\%) dentre outras. ${ }^{5}$

No estudo de Oliveira e Giro (2011) ${ }^{9}$ fica evidenciado que o conhecimento da Síndrome de Down é de grande interesse para a comunidade científica, pois seus portadores apresentam uma série de alterações craniofaciais e dentárias. Estima-se que, no Brasil, apenas poucos dentistas sejam habilitados a atender a esse grupo de pacientes especiais, cujo tratamento se torna dificultado pelo pouco conhecimento acerca das suas principais características bucais. ${ }^{6.8}$ 
Como exposto por Castro et al., $(2010)^{10}$, as características gerais dos portadores dessa síndrome são: faces achatadas, orientação mongoloide das fendas palpebrais, epicanto, nariz em sela pequeno, deformidades das orelhas, braquicefalia, região occipital achatada, pescoço curto e achatado, baixa estatura, mão e pés pequenos e largos. São relatadas ainda alterações do sistema endócrino-metabólico, envolvendo principalmente as glândulas da tireoide e pituitária, e no sistema hematológico e gastrointestinal, além de cardiopatia congênita e apneia do sono. ${ }^{3,9}$

Santos $(2014)^{11}$ relata que a Síndrome de Down é uma condição autossômica congênita em que se observa coordenação motora deficiente, coeficiente de inteligência (QI) reduzido, desenvolvimento facial alterado devido à hipotonia muscular, que acomete inclusive o sistema estomatognático (bucal), hiperflexibilidade de todo o corpo(no lactente e na primeira infância) e envelhecimento precoce.

Para Marta $(2011)^{12}$, dentre os órgãos que compõem o sistema estomatognático, podem estar alterados, no paciente com trissomia do cromossomo 21 , os dentes, a língua, o periodonto, a maxila, a mandíbula, a oclusão, além da articulação temporomandibular. $\mathrm{O}$ paciente sindrômico pode apresentar macroglossia e língua fissurada. ${ }^{7}$

A macroglossia, que se caracteriza por um crescimento excessivo da musculatura e tem origem congênita, pode determinar no deslocamento dos dentes e má oclusão ${ }^{10}$. Diante disso, Marta $(2011)^{12}$ menciona em seu estudo que os mecanismos compensatórios conduzem à protusão e consequente abertura bucal, levando o paciente à condição de respirador bucal. As cirurgias geralmente não são recomendadas, porque, além do problema central não ser a língua, mas sim a cavidade bucal, elas podem interferir no paladar e não auxiliar na melhora da articulação.

A língua fissurada caracteriza-se como uma malformação que se manifesta clinicamente por numerosos pequenos sulcos ou ranhuras na superfície dorsal, que se irradiam do sulco central da língua. Outro fator importante relacionado à hipotoni- cidade muscular encontrada no portador da Síndrome de Down, descrito no estudo de Castro et al., $(2010)^{10}$, é o excesso de saliva nas comissuras bucais, o que leva a irritação e fissuras, facilitando a instalação de processos infecciosos pelo acúmulo de microrganismos como Candida albicans, ao que se associa a falta de higiene local. ${ }^{12}$

\section{Os dentes dos}

portadores da

Síndrome de

Down apresentam

mineralização

completa, mas, além

de sofrerem atraso,

mostram alteração na sequência de erupção, principalmente

\section{dos decíduos}

Determinados grupos populacionais apresentam maior susceptibilidade a doença periodontal, como os pacientes especiais, incluídos aqui os portadores da Síndrome de Down. O'keefe (2010) ${ }^{13}$ afirma em seu trabalho que os efeitos diretos são os fatores microbianos que atuam diretamente sobre os tecidos causando-lhes danos, e os efeitos indiretos são os fatores autolesivos produzidos pelo hospedeiro, como respostas inflamatórias e fenômenos imunológicos, em resposta à agressão bacteriana. ${ }^{14}$

Com relação aos aspectos craniofaciais, observa-se a micrognatia, caracterizada por maxilar pequeno, podendo afetar ocasionalmente a mandíbula. A micrognatia do maxilar, de acordo com O'keefe $(2010)^{13}$, é geralmente devida a uma defi- ciência na área pré-maxilar, e os pacientes com esta deformidade tem o terço médio da face retraído. Acredita-se que a micrognatia seja a maior responsável pelo desenvolvimento da respiração bucal, principal característica bucal, devido à associação com alterações de desenvolvimento das estruturas nasais e nasofaringeanas. ${ }^{10}$

Em relação á mandíbula, como retrata Dehaitem et al $(2008)^{14}$, esta pode se apresentar expandida transversalmente em função de pressões linguais. Como consequência o portador apresenta distúrbios da articulação temporomandibular associados à hipotonicidade muscular generalizada e alteração do disco articular. A cronologia de erupção dos dentes decíduos e permanentes é variada, muitas vezes se apresentando retardada, e geralmente a dentição decídua não está completa até aos quatro ou cinco anos de idade. ${ }^{5,13}$

Os dentes dos portadores da Síndrome de Down apresentam mineralização completa, mas, além de sofrerem atraso, mostram alteração na sequência de erupção, principalmente dos decíduos. Rapalo et al $(2010)^{15}$ destaca que microdontia e hipoplasia de esmalte, assim como hipodontia e oligodontia, são as anomalias dentárias mais encontradas. As anomalias estruturais incluem a taurodontia, os dentes conoides, fusões e germinações, sendo os caninos mais afetados em forma e tamanho. ${ }^{1,4}$

Observa-se, ainda, nos pacientes com Síndrome de Down, palato em ogiva, tonsilas e adenoides hipertrofiadas, úvula bífida, fenda labial e palatina. A má oclusão é frequentemente encontrada nos portadores da Síndrome de Down, predominando a classe III de Angle, mordida cruzada posterior, pseudoprognatismo e mordida aberta anterior. De acordo com o estudo de Idaira et al., $(2010)^{16}$, o aumento da idade do indivíduo está relacionada com a tendência ao desenvolvimento de má oclusão e a combinação com outros problemas como disfunção motora oral, redução do tônus muscular da boca e da face, o que pode levar a alterações da fala, mastigação e deglutição. ${ }^{15}$

Para Anders e Davis (2010) ${ }^{17}$, o bruxismo também é observado, sendo mais 
comum no período noturno, levando ao consequente desgaste uniforme do esmalte dentário. A posição dos dentes também desempenha um papel importante em determinadas circunstâncias, favorecendo o acúmulo de alimentos e resíduos. Se considerarmos que, em geral, pacientes com necessidades especiais possuem uma saúde bucal deficiente e uma higienização precária, poderíamos concluir que o paciente sindrômico apresenta índice de cárie alto. Entretanto, isso não acontece, uma vez que a macroglossia e o processo salivar são fatores que determinam o baixo índice de cárie.

Por fim, Stefanovska et al., $(2010)^{18}$ declara que além das alterações imunológicas, outros fatores são propostos para explicar a alta prevalência da doença periodontal e o aumento da sua severidade em portadores da síndrome, incluindo a má oclusão, a colonização precoce e um elevado número de periodontopatógenos, em especial o Porphyromonas gingivalis. ${ }^{21,6}$

\section{CONCLUSÃO}

A partir das informações obtidas conclui-se que, a síndrome de Down é uma doença congênita multissistêmica, associada a várias anormalidades crânio-faciais e dentais, retardo mental e malformações físicas. Pacientes com trissomia do cromossomo 21 podem ser tratados clinicamente por profissionais da odontologia, desde que se tomem os cuidados necessários. A higiene bucal supervisionada é fundamental nesses indivíduos, devido às limitações motoras e à alta prevalência de doenças periodontais.

A correta avaliação do crescimento e desenvolvimento, principalmente nos primeiros anos, permite a detecção de problemas que podem impedir o pleno desenvolvimento do indivíduo. Um acompanhamento regular por dentistas, para que seja promovido o bem-estar necessário nas diversas áreas de desempenho humano, visa ao enriquecimento da qualidade de vida do paciente.

Fica exposto que se faz necessário o incentivo a publicação de mais artigos científicos na área. Faz-se oportuno considerar os trabalhos já descritos na comunidade acadêmica, no intuito de fortalecer pesquisas futuras sobre este tema. Como revela o artigo, são vários os autores que procuram deixar clara a importância do papel do profissional de odontologia no acompanhamento de pessoas com Síndrome de Down.

\section{REFERÊNCIAS}

1. Almeida, M. F. A. A oliveira, A, C, O, Schitkoski, M, C, Frasson, A, C. Educação nutricional e qualidade de vida para portadores de sindrome de down (SD). FIEP BULLETIN - 2015. v. 85, n. 2.

2. Corrêa, J. C. F, Oliveira, A. R, Oliveira, C. S, Corrêa, I,C. A existência de alterações neurofisiológicas pode auxiliar na compreensão do papel da hipotonia no desenvolvimento motor dos indivíduos com síndrome de Down? Fisioterapia e Pesquisa, São Paulo, 2011. v.18, n.4.

3. Brasil. Ministério da Saúde. Diretrizes de atenção à pessoa com Síndrome de Down, 1ed., Brasília, 2012.

4. Gorla J. L, Duarte E, Costa LT, Freire, F. Crescimento de crianças e adolescentes com Síndrome de Down - Uma breve revisão de literatura. Rev Bras Cineantropom Desempenho. 2011. v. 13, n 3.

5. Glassman P, Caputo A, Dougherty N, Lyons R, Messieha Z, Miler $\mathrm{C}$, et al. Special Care Dentistry Association consensus statement on sedation, anesthesia and alternative techniques for people with special needs. Spec Care Dent. 2009; 29: 2-8.

6. Lace A, Martins, M. R. I. Conhecimento da habilidade motora e fatores clinicos de crianças com sindrome de Down e a sobrecarga de seus cuidadores. Arq. Ciênc. Saúde. 2014. v, 22, n. 1.

7. Carvalho A. C. A; Campos, P. S. F; Crusoé-Rebello, I. Síndrome de Down: aspectos relacionados ao sistema estomatognático. R. Ci. méd. biol. 2010; 9(Supl.1):49-52

8. Oliveira, A. C; Czeresniai, D; Paiva, S. M; Campos, M. R; Ferreira, E. F. Uso de serviços odontológicos por pacientes com síndrome de Down. Rev. Saúde Pública 2008. vol.42 no.4

9. Oliveira, A. L. B. M; Giro, E. M. A Importância da abordagem precoce no tratamento odontológico de pacientes com necessidades especiais. Odonto 2011; 19 (38): 45-51
10. Castro A. M, Marchesoti M. G. N, Oliveira F. S, Novaes M. S. $P$ Avaliação do tratamento odontológico de pacientes com necessidades especiais sob anestesia geral. Rev Odontol UNESP. 2010; 39(3): 137-142.

11. Santos, T. D. N. Perspectivas de abordagem a criança com Síndrome de Down: uma revisão integrativa da literatura Universidade de Brasília. Faculdade de Ceilândia. Curso de Enfermagem, 2014.

12. MARTA, S. N. Programa de assistência odontológica ao paciente especial: uma experiência de 13 anos. RGO, Rev. gaúch. odontol. (Online) 2011. v. 59 n.3.

13. O'keefe E. Oral health of patients with intellectual disabilities. Evid Based Dent. 2010;11(3):81.

14. Dehaitem M. J, Ridley K, Kerschbaum W. E, Inglehart M. R. Dental hygiene education about patients with special needs: a survey of U.S. programs. J Dent Educ. 2008;72(9):1010-9.

15. Rapalo D. M, Davis J. L, Burtner P, Bouldin E. D. Cost as a barrier to dental care among people with disabilities: a report from the Florida behavioral risk factor surveillance system. Spec Care Dent. 2010;30(4):133-9.

16. Idaira Y, Nomura Y, Tamaki Y, Katsumura S, Kodama S, Kurata $K$, Asada $Y$. Factors affecting the oral condition of patients with severe motor and intellectual disabilities. Oral Dis. 2008;14(5):435-9.

17. Anders P. L, Davis E. L. Oral health of patients intellectual disabilities: a systematic review. Spec Care Dent. 2010;30(3):110-7.

18. Stefanovska E, Nakova M, Radojkova-Nikolovska V, Ristoska S. Tooth-brushing intervention programme among children with mental handicap. Bratisl Lek Listy. 2010;111(5):299-302. 